\title{
Speed Estimation Using Extended Filter Kalman for the Direct Torque Controlled Permanent Magnet Synchronous Motor (PMSM)
}

\author{
M. S. Merzoug and H. Benalla \\ LEC- Research Laboratory de Constantine \\ Department of Electrical Engineering \\ Constantine, \\ Algeria
}

\section{Introduction}

Permanent magnet (PM) synchronous motors have attracted increasing interest in recent years for industrial drive application. The high efficiency, high steady state torque density and simple controller of the PM motor drives compared with the induction motor drives make them a good alternative in certain applications. Moreover, the availability of low-cost power electronic devices and the improvement of PM characteristics enable the use of PM motors even in some more demanding applications. Advantages of PMSM include low inertia, high efficiency, high power density and reliability. Because of these advantages, PMSM are indeed excellent for use in high-performance servo drives where a fast and accurate torque response is required. In PMSM drives, the electromagnetic torque is usually controlled indirectly via the stator current components in a reference frame fixed to the rotor flux field. The idea of combining the advantages of DTC and PMSM into a highly dynamic drive appeared in the literature in the late 1990's. In the past decade several authors have proposed ways to adapt DTC to work with PMSM.

Moreover DTC uses no current controller and no motor parameters other than the stator resistance, which yields a faster torque response and lower parameter dependence than with field oriented control.

Recently, motor drive systems without electromechanical sensors, so called 'sensorless drives', have gained increasing popularity in industrial applications because of inherent drawbacks of electromechanical sensors. In general, electromechanical sensors are used to obtain speed or position information of motors. A drawback of these sensors is performance degradation due to vibration or humidity .

Consequently, the extended Kalman filter is considered to be the best solution for the speed estimation of an induction motor. The extended Kalman filter has been applied to the direct torque control control system .

\section{The Model of PMSM}

The electrical and mechanical equations of the PMSM in the rotor reference (d-q) frame are as follows [6]: 


$$
\left\{\begin{array}{c}
\frac{d}{d t} I_{d}=-\frac{R_{s}}{L_{d}} I_{d}+\omega_{r} \frac{L_{q}}{L_{d}} I_{q}+V_{d} \\
\frac{d}{d t} I_{q}=-\frac{R_{s}}{L_{q}} I_{q}-\omega_{r} \frac{L_{d}}{L_{q}} I_{d}-\frac{1}{L_{q}} \varphi_{f} \omega_{r}+V_{q} \\
\varphi_{d}=L_{d} I_{d}+\varphi_{f} \\
\varphi_{q}=L_{q} I_{q}
\end{array}\right.
$$

And the electromagnetic torque $T_{e}$ is given by:

$$
\left.T_{e}=\frac{3}{2} P\left[\left(L_{d}-L_{q}\right) I_{d} I_{q}+I_{q} \varphi_{f}\right)\right]
$$

The equation for the motor dynamics, on the other hand is

$$
T_{e}-T_{L}-T_{f}=J \frac{d \Omega}{d t}
$$

Figure. 1, presents the model of PMSM in d-q axis

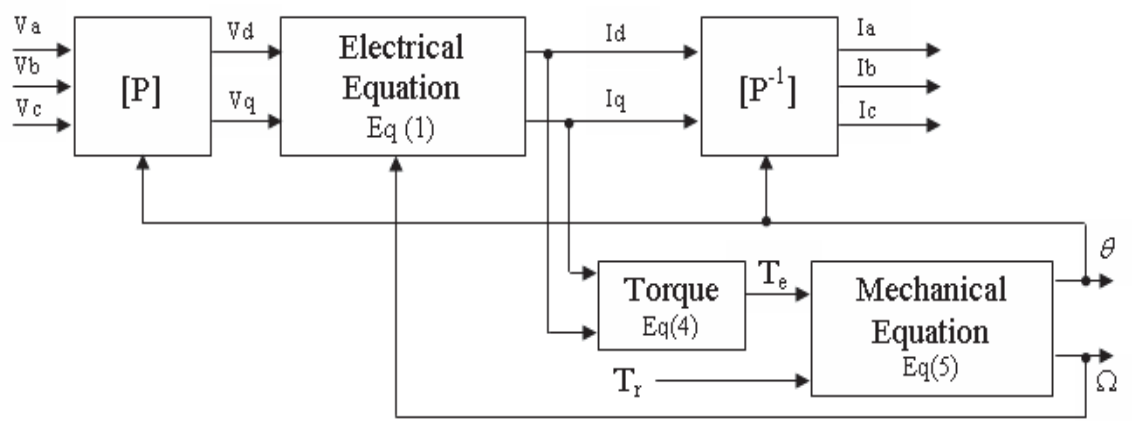

Fig. 1. Model of PMSM in d-q axis.

\section{Direct torque control system}

Since M. Depenbrock and I. Takahashi proposed Direct Torque Control (DTC) for induction machines in the middle of 1980's, more than one decade has passed. It is getting more and more popular nowadays. The basic idea of DTC for induction motor is to control the torque and flux linkage by selecting the voltage space vectors properly, which is based on the relationship between the slip frequency and torque.

\subsection{Estimation of the torque and the flux linkage}

The basic principle of the DTC is to select proper voltage vectors using a pre-defined switching table. The selection is based on the hysteresis control of the stator flux linkage and the torque. In the basic form the stator flux linkage is estimated with: 


$$
\varphi_{s}(t)=\int_{0}^{t}\left(V s-R_{s} I_{s}\right) d t+\varphi_{s 0}
$$

Let us replace the estimate of the stator voltage with the true value and write it as:

$$
V_{S}\left(S_{A} ; S_{B} ; S_{C}\right)=\frac{2}{3} U_{0}\left(S_{A}+S_{B} e^{j 2 \pi / 3}+S_{C} e^{j 4 \pi / 3}\right)
$$

$\mathrm{Sa}, \mathrm{Sb}$ and $\mathrm{Sc}$ represent the states of the three phase legs 0 meaning that the phase is connected to the negative and 1 meaning that the phase is connected to the positive leg. The stator current space vector is calculated from measured currents $i_{a}, i_{b}, i_{c}$ :

$$
i_{S}=\frac{2}{3}\left(i_{a}+i_{b} e^{J 2 \pi / 3}+i_{c} e^{j 4 \pi / 3}\right)
$$

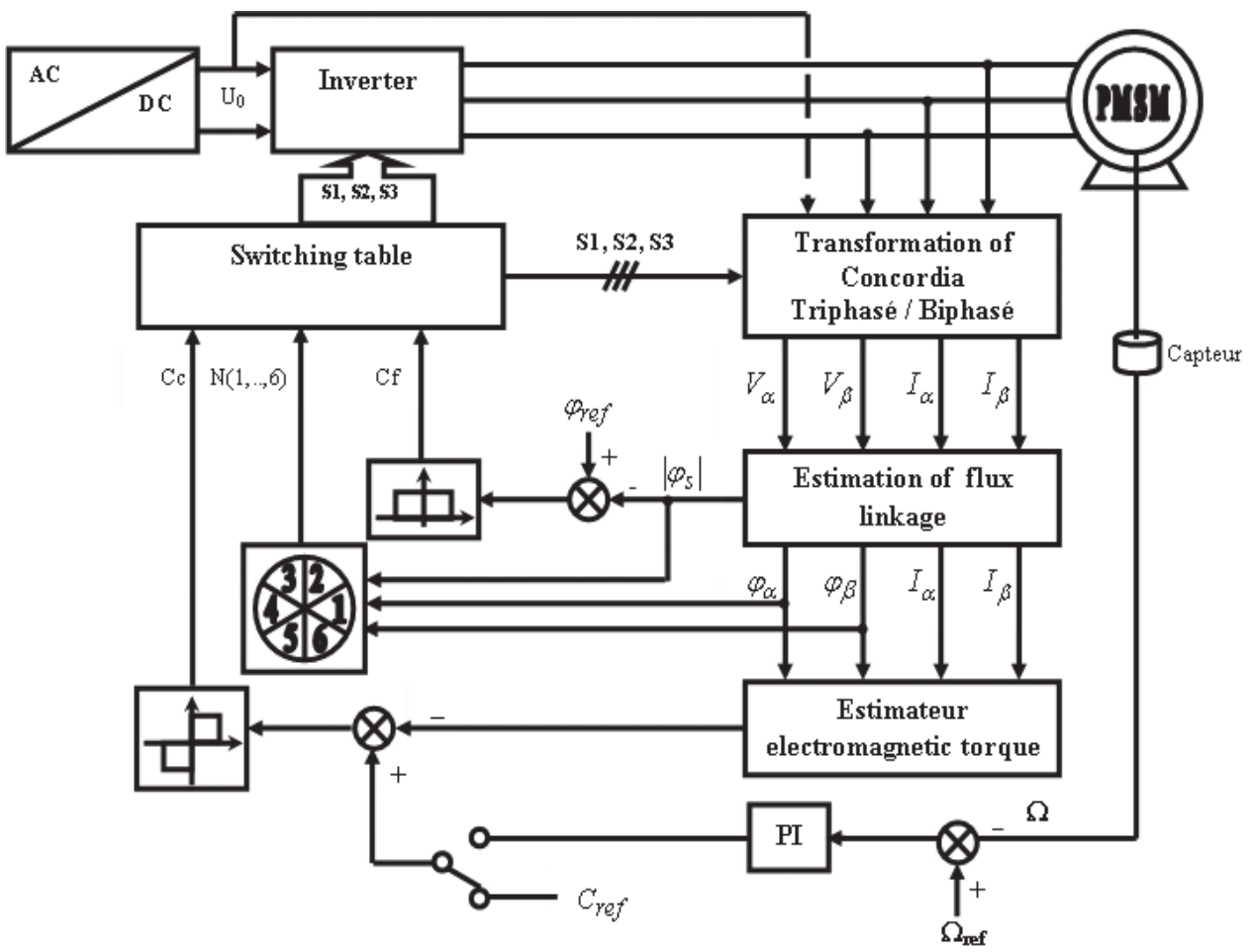

Fig. 2. System diagram of a typical DTC PMSM drive system. 
The voltage vectors obtained this way are shown in Figure 3.

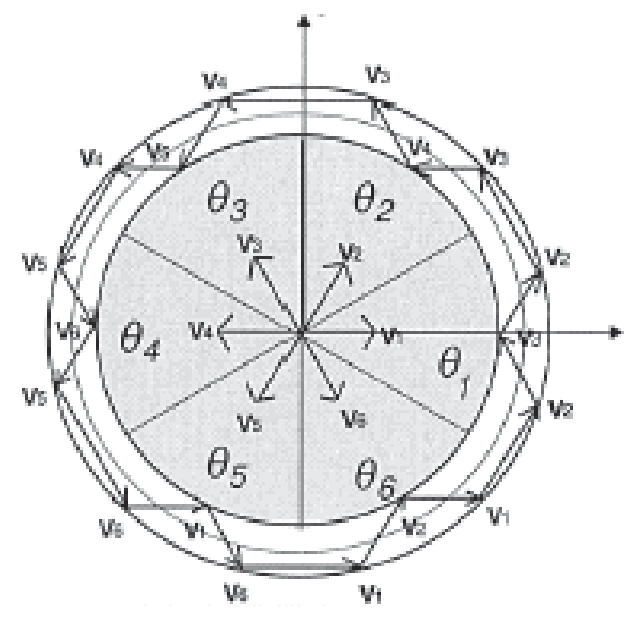

Fig. 3. Voltage vectors for DTC.

The composite $\alpha$ and $\beta$ of vector $\varphi_{s}$ can be obtained:

$$
\left\{\begin{aligned}
\varphi_{S \alpha} & =\int_{0}^{t}\left(V_{S \alpha}-R_{S} I_{S \alpha}\right) d t \\
\varphi_{S \beta} & =\int_{0}^{t}\left(V_{S \beta}-R_{S} I_{S \beta}\right) d t
\end{aligned}\right.
$$

Stator flux linkage written:

$$
\varphi_{s}=\sqrt{\left(\varphi_{S \alpha}\right)^{2}+\left(\varphi_{S \beta}\right)^{2}}
$$

The angle $\theta_{S}$ is equal to:

$$
\theta_{S}=\operatorname{arctg} \frac{\varphi_{S \beta}}{\varphi_{S \alpha}}
$$

The torque can then be estimated with:

$$
T_{e}=\frac{3}{2} P\left(\varphi_{S \alpha} I_{S \beta}-\varphi_{S \beta} I_{S \alpha}\right)
$$

The voltage vector plane is divided into six sectors so that each voltage vector divides each region into two equal parts. In each sector, four of the six non-zero voltage vectors may be used. Also zero sectors are allowed. All the possibilities can be tabulated into a switching table (Table I). The output of the torque hysteresis comparator is denoted as $\tau$, the output of the flux hysteresis comparator as $\phi$ and the flux linkage sector is denoted as $\theta$. 


\begin{tabular}{|c|c|c|c|c|c|c|c|}
\hline \multicolumn{2}{|c|}{$\theta, \tau, \phi$} & $\theta_{1}$ & $\theta_{2}$ & $\theta_{3}$ & $\theta_{4}$ & $\theta_{5}$ & $\theta_{6}$ \\
\hline \multirow{4}{*}{$\phi=1$} & $\tau=1$ & $\mathrm{~V}_{2}$ & $\mathrm{~V}_{3}$ & $\mathrm{~V}_{4}$ & $\mathrm{~V}_{5}$ & $\mathrm{~V}_{6}$ & $\mathrm{~V}_{1}$ \\
\cline { 2 - 8 } & $\tau=0$ & $\mathrm{~V}_{7}$ & $\mathrm{~V}_{0}$ & $\mathrm{~V}_{7}$ & $\mathrm{~V}_{0}$ & $\mathrm{~V}_{7}$ & $\mathrm{~V}_{0}$ \\
\cline { 2 - 8 } & $\tau=-1$ & $\mathrm{~V}_{6}$ & $\mathrm{~V}_{1}$ & $\mathrm{~V}_{2}$ & $\mathrm{~V}_{3}$ & $\mathrm{~V}_{4}$ & $\mathrm{~V}_{5}$ \\
\hline \multirow{3}{*}{$\phi=0$} & $\tau=1$ & $\mathrm{~V}_{3}$ & $\mathrm{~V}_{4}$ & $\mathrm{~V}_{5}$ & $\mathrm{~V}_{6}$ & $\mathrm{~V}_{1}$ & $\mathrm{~V}_{2}$ \\
\cline { 2 - 8 } & $\tau=0$ & $\mathrm{~V}_{0}$ & $\mathrm{~V}_{7}$ & $\mathrm{~V}_{0}$ & $\mathrm{~V}_{7}$ & $\mathrm{~V}_{0}$ & $\mathrm{~V}_{7}$ \\
\cline { 2 - 8 } & $\tau=-1$ & $\mathrm{~V}_{5}$ & $\mathrm{~V}_{6}$ & $\mathrm{~V}_{1}$ & $\mathrm{~V}_{2}$ & $\mathrm{~V}_{3}$ & $\mathrm{~V}_{4}$ \\
\hline
\end{tabular}

Table 1. Switching Table Presented By Takahashi and Noguchi.

\section{Kalman filter}

The Kalman filter was developed by R.E. Kalman in 1960. Due to advances in the development of digital computing, the Kalman filter is a subject of extensive research and application. Kalman filtering has been applied in the areas of aerospace, navigation, manufacturing, and many others. [9]

The Kalman filter provides a means for inferring missing information from indirect (and noisy) measurements. It provides the optimal (minimum variance) state estimate when the dynamic system is linear and the statistical characteristics of the various noise elements are know

The EKF is an optimal recursive estimation algorithm based on the least-square sense for estimating the states of dynamic nonlinear systems. That is, it is an optimal estimator for computing the conditional mean and covariance of the probability distribution of the state of a nonlinear stochastic system with uncorrelated Gaussian process and measurement noise.

Since the state models are nonlinear, the EKF can be applied to estimate state variables. In this case, the back-EMF is considered as a state variable. Nonlinear discrete models with white noise are given as follows:

$$
\left\{\begin{array}{l}
x(k+1)=F(x(k), u(k))+w(k) \\
y(k)=h(x(k))+v(k)
\end{array}\right.
$$

$\mathrm{w}$ and $\mathrm{v}$ are the system and measurement noise.

For linearization process in the model, the partial derivative is introduced and discrete state models are: [10]

$$
\begin{gathered}
F(k)=\left.\frac{\partial f(x(k), u(k))}{\partial x^{T}(k)}\right|_{x(k)=\hat{x}(k / k)} \\
H(k)=\left.\frac{\partial f(x(k))}{\partial x(k)}\right|_{x(k)=\hat{x}(k / k)}
\end{gathered}
$$

Estimation of an error covariance matrix

$$
P^{-}(k+1)=F(k) \cdot P(k) \cdot F^{T}+Q
$$


Computation of a Kalman filter gain

$$
K(k+1)=P^{-}(k+1) H^{T}(k)\left[H(k) P^{-}(k+1) H(k)^{T}+R\right]^{-1}
$$

Update of a error covariance matrix

$$
P(k+1)=(I-K(k+1) \cdot H(k)) P^{-}(k+1)
$$

State estimation

$$
\hat{X}(k+1)=\hat{X}(k)+K(k+1)[y(k+1)-h(\hat{X}(k+1))]
$$

Where:

$P^{-}(k+1)$ is a priori error covariance matrix

$Q$ and $R$ respectively and are independent from the system state [4].

\section{EKF implementation for a PMSM}

The extended Kalman filter implementation for a PMSM motor requires three basic steps.

- Continuous PMSM model

- Discretization of the PMSM motor model

- Simulation

\subsection{Continuous PMSM model}

The model of PMSM in the d-q reference frame can be written:

$$
\left\{\begin{array}{l}
L_{d} \frac{d}{d t} I_{d}=V_{d}-R_{s} I_{d}+P \Omega L_{q} I_{q} \\
L_{q} \frac{d}{d t} I_{q}=V_{q}-R_{s} I_{q}-P \Omega\left(L_{d} I_{d}+\varphi_{f}\right) \\
J \frac{d \Omega}{d t}=T_{e}-T_{L}-f \Omega \\
\frac{d \theta}{d t}=\Omega
\end{array}\right.
$$

The system can be modeled as :

$$
\frac{d}{d t}\left[\begin{array}{c}
I_{d} \\
I_{q} \\
\Omega \\
\theta
\end{array}\right]=\left[\begin{array}{cccc}
-\frac{R_{s}}{L d} & P \Omega \frac{L_{q}}{L d} & 0 & 0 \\
-P \Omega \frac{L_{d}}{L_{q}} & -\frac{R_{s}}{L_{q}} & -P \frac{\varphi_{f}}{L_{q}} & 0 \\
0 & 0 & -\frac{f}{J} & 0 \\
0 & 0 & 0 & 1
\end{array}\right]\left[\begin{array}{c}
I_{d} \\
I_{q} \\
\Omega \\
\theta
\end{array}\right]+\left[\begin{array}{c}
\frac{1}{L_{d}} \\
\frac{1}{L_{q}} \\
-\frac{1}{J} \\
0
\end{array}\right]\left[\begin{array}{c}
V_{d} \\
V_{q} \\
T_{L} \\
0
\end{array}\right]
$$


We are measuring current $\mathrm{I}_{\mathrm{d}}$ and $\mathrm{I}_{\mathrm{q}}$.

$$
\left[\begin{array}{c}
I_{d} \\
I_{q}
\end{array}\right]=\left[\begin{array}{llll}
1 & 0 & 0 & 0 \\
0 & 1 & 0 & 0
\end{array}\right]\left[\begin{array}{c}
I_{d} \\
I_{q} \\
\Omega \\
\theta
\end{array}\right]
$$

\subsection{Discretization of the PMSM model}

The corresponding discrete time model is given by:

$$
\begin{gathered}
X_{(k+1)}=A_{d} \cdot X_{(k)}+B_{d} \cdot u_{(k)} \\
y_{(k+1)}=C_{d} \cdot X_{(k)}
\end{gathered}
$$

The conversion is done by the following approximation;

$$
\left\{\begin{array}{l}
A_{d}=e^{A t}=I+A T s \\
B_{d}=\int_{0}^{t} e^{A \xi} B d \xi=B \cdot T s \\
C_{d}=C
\end{array}\right.
$$

We are assuming that the sampling -time $\mathrm{T}_{\mathrm{S}}$ is very small compared to the system dynamics. The discrete model of the PMSM motor is given as:

$$
f(x(k), u(k))=\left[\begin{array}{c}
\left(1-T_{s} \frac{R_{s}}{L_{d}}\right) I_{d}+p \Omega T_{s} \frac{L_{q}}{L_{d}} I_{q}+T_{s} \frac{1}{L_{d}} v_{d} \\
\left(-p \Omega T_{s} \frac{L_{d}}{L_{q}}\right) I_{d}+\left(1-T_{s} \frac{R_{s}}{L_{q}}\right) I_{q}-T_{s} \frac{\varphi_{f}}{L_{q}} p \Omega+T_{s} \frac{1}{L_{q}} v_{q} \\
P T_{s} \frac{L_{d}-L_{q}}{J} I_{q} I_{d}+p T_{s} \frac{\varphi_{f}}{J} I_{q}+\left(1-T_{s} \frac{f}{J}\right) \Omega-T_{s} \frac{1}{J} T_{L} \\
\theta+T_{s} \Omega
\end{array}\right]
$$

\subsection{Simulation and implementation}

The matrices linearization $\mathrm{F}$ and $\mathrm{H}$, we can linearize the system in every moment of operation. They are given as follows

$$
F(k)=\left[\begin{array}{cccc}
1-T s \frac{R_{s}}{L d} & P \Omega T s \frac{L_{q}}{L d} & T s \frac{P L_{q}}{L d} I_{q} & 0 \\
-P \Omega T s \frac{L_{d}}{L_{q}} & 1-T s \frac{R_{s}}{L_{q}} & -\frac{T s}{L_{q}}\left(P L_{d} I_{d}+P \varphi_{f}\right) & 0 \\
P T s \frac{L d-L q}{J} I_{q} & P T s\left(\frac{L d-L q}{J} I_{d}+\frac{\varphi}{J}\right) & 1-T s \frac{f}{J} & 0 \\
0 & 0 & T s & 1
\end{array}\right]
$$




$$
\begin{gathered}
h=\left[\begin{array}{c}
I_{d} \\
I_{q}
\end{array}\right] \\
\frac{\partial H}{\partial X}=\left[\begin{array}{llll}
1 & 0 & 0 & 0 \\
0 & 1 & 0 & 0
\end{array}\right]
\end{gathered}
$$

\subsection{Observer torque load}

The method proposed by Pioufle can be estimated the torque load, Figure 4, illustrates the principle of the estimate. [11]

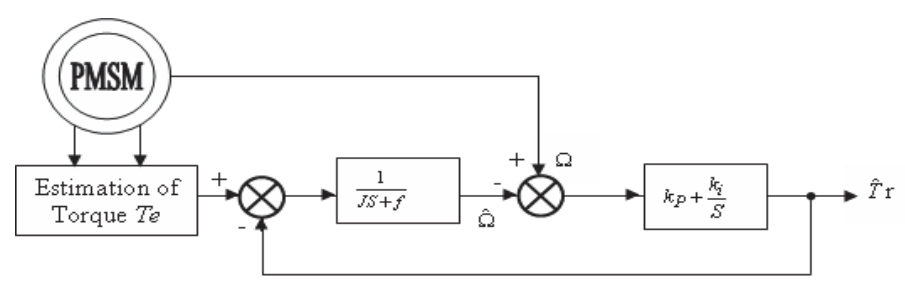

Fig. 4. Estimation load torque.

The error between the speed measured and the estimated speed entry is presented as a regulator PI whose output is

$$
\hat{T}_{L}=\frac{1+\frac{k p}{k_{i}} S}{1+\frac{1+k_{p}}{k_{i}} S+\frac{1}{k_{i}} S^{2}} T_{L}
$$

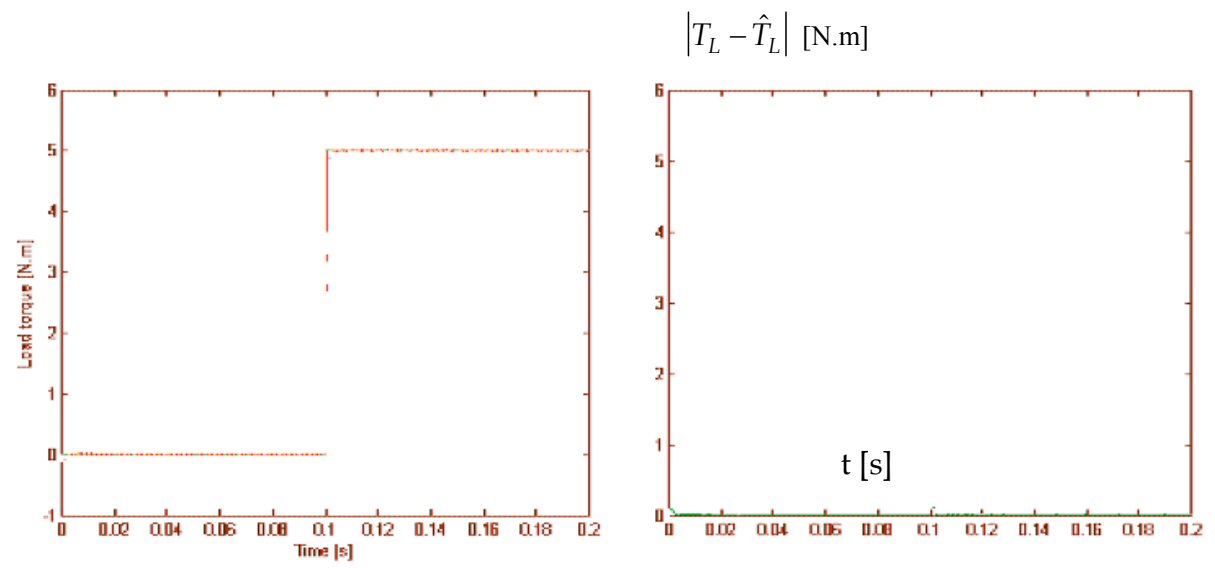

Fig. 5. Estimation load torque. 


\section{Sensitivity study and simulation results}

Computer simulations have been carried out in order to validate the effectiveness of the proposed scheme. The speed current and rotor position responses are observed under various operating conditions such as change in reference speed, step change in load and parameter variation.

\section{Simulation results}

Extensive simulations have been performed using Matlab/ Simulink Software to examine control algorithm of the DTC applied for PMSM presented in Figure 6.

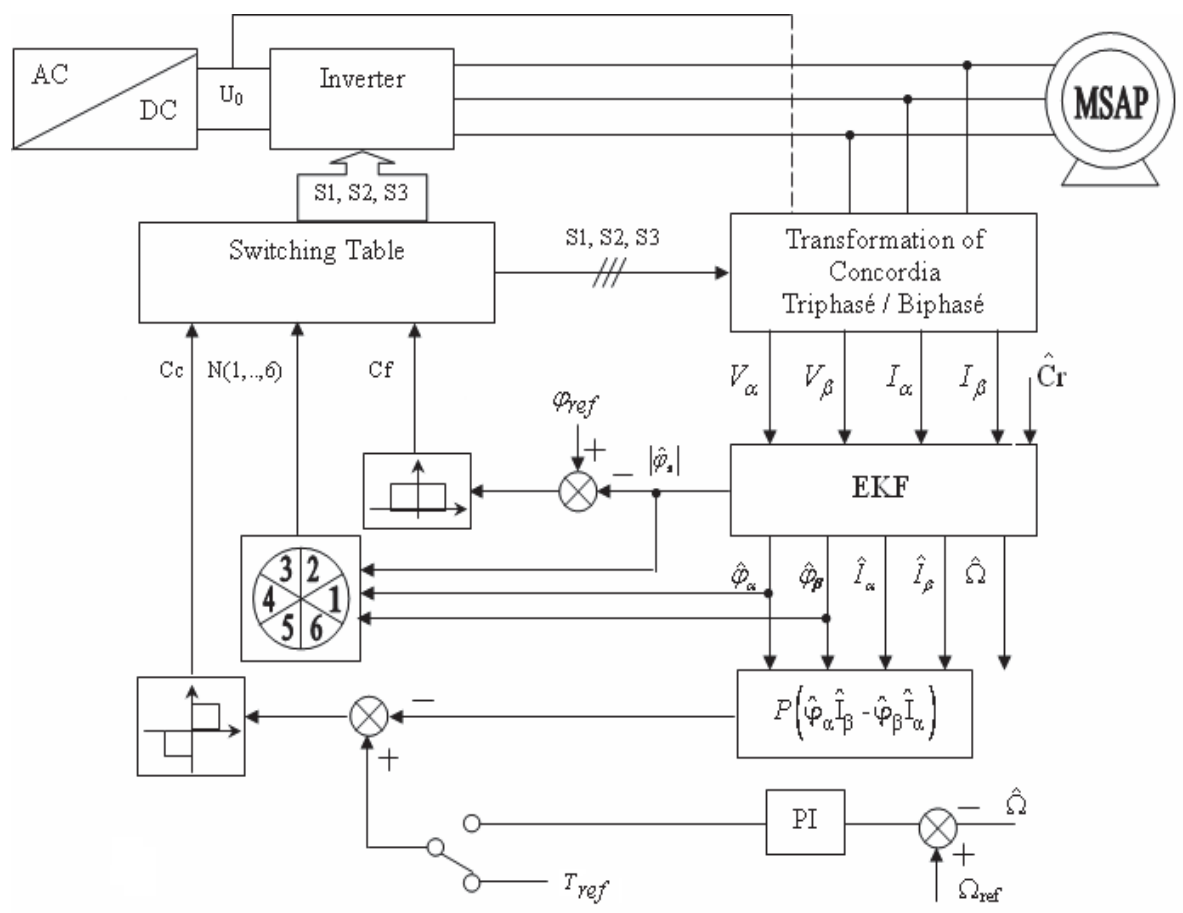

Fig. 6. Basic DTC for sensorless PMSM drive.

\subsection{Regulation speed}

The simulation results of the DTC where to apply a torque load equal to 5 N.m at $t=0.1 \mathrm{~s}$ and a reference speed equal to $100 \mathrm{rad} / \mathrm{s}$. 
Figure 7, shows the actual and estimated speed of the proposed PMSM sensorless scheme, these responses illustrate high performance of the proposed EKF observer during transients and steady state.

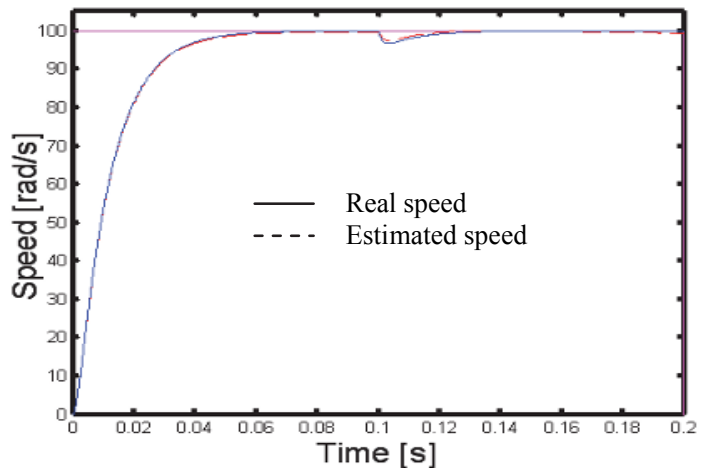

Fig. 7. Actual and estimated speed.

Figure 8, present the speed zoom with and without torque compensation.

Figure 9, presents the estimated electromagnetic torque. The torque follows perfectly the value of record with negligible effect on the speed that is rapidly restored to its reference.

Figure 10, presents the estimated flux, we also note that the flow is not affected by the variation of the load. The flux reaches its reference control with no overshoot.

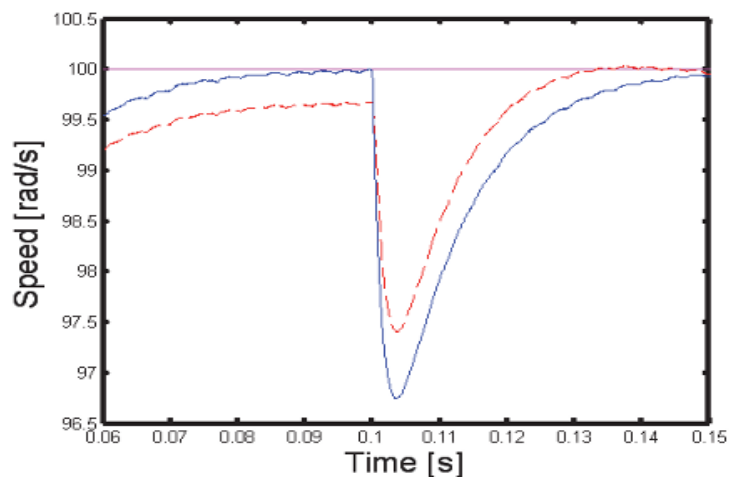

Fig. 8. Speed zoom. 


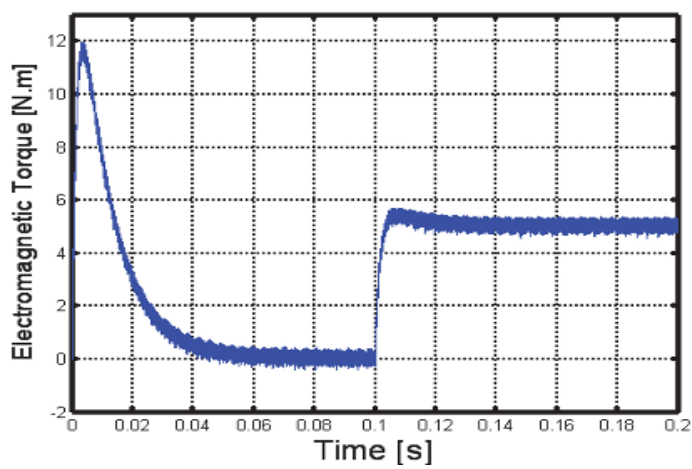

Fig. 9. Estimated electromagnetic torque.

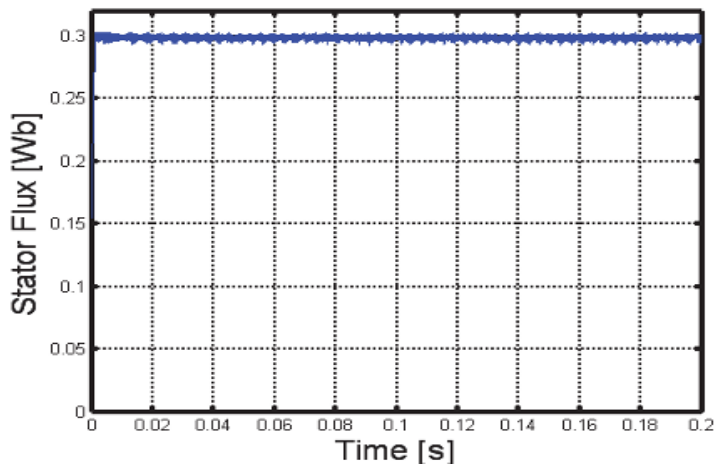

Fig. 10. Estimated stator flux.

\subsection{Inversion of the speed}

To test the robustness of technical command at the reverse direction of rotation, it introduced a change in record speed reference $+100 \mathrm{rad} / \mathrm{s}$ to $-100 \mathrm{rad} / \mathrm{s}$ time $\mathrm{t}=0.1 \mathrm{~s}$ after a torque load equal to $3 \mathrm{Nm}$, Figure 11.

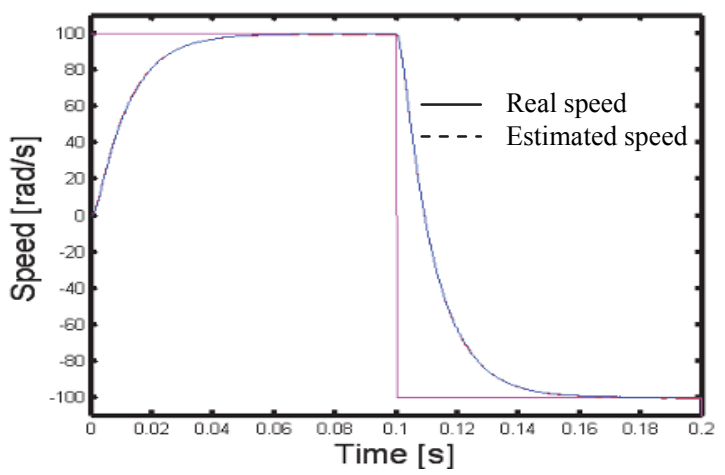

Fig. 11. Actual and estimated speed. 


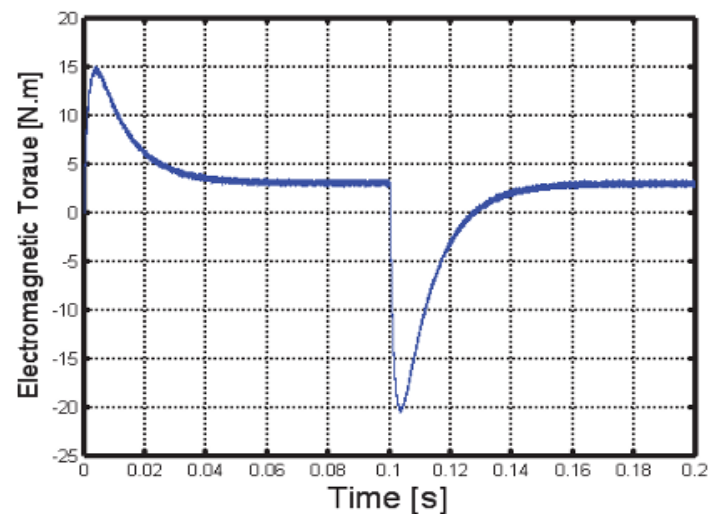

Fig. 12. Estimated electromagnetic torque.

The estimation algorithm is robust because the variation of the speed is important and the estimated speed follows the real speed when the motor starts and at the moment of speed inversion.

Figure 13. Presents trajectory of the estimated stator flux components, the stator flux trajectory is almost circular

Figure 14. Shows the rotor position.

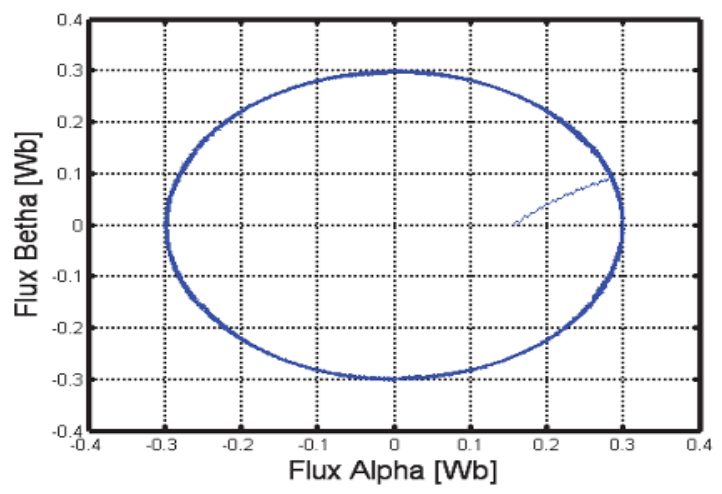

Fig. 13. Trajectory of the estimated stator flux 


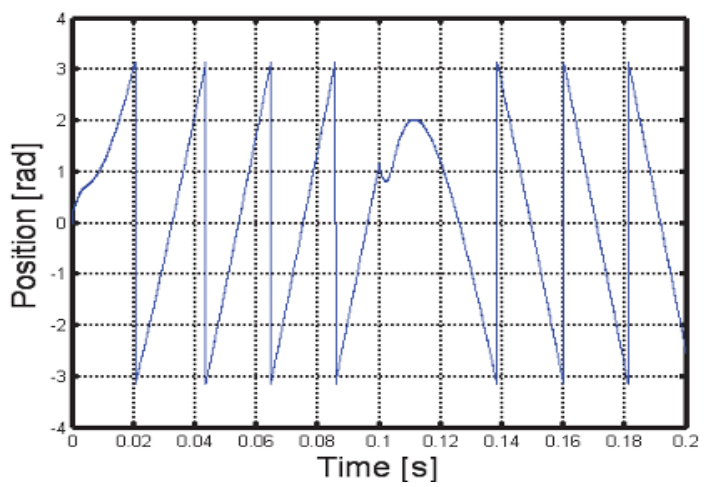

Fig. 14. Evolution of rotor position

\section{Conclusion}

In this paper, the EKF approach for a speed sensorless direct torque control (DTC) is proposed to estimate the rotor position and speed. The performance of the algorithm was investigated over a wide range of speeds. Overall, the simulation results obtained for estimating the speed and position are very satisfactory viewpoint estimation error, strength and stability of global training system in any operating condition.

\section{References}

Kawata, T.; Kosaka, M. \& H. Uda. (2003). Sensorless IPMSM drive with EKF estimation of speed and rotor position, SICE Annual Conference in Fukui

Mademlis, C. \& Agelidis, G. (2001). On Considering Magnetic Saturation with Maximum Torque to Current Control in Interior Permanent Magnet Synchronous Motor Drives, IEEE Trans. Energy Conversion, vol. 16, no. 3, Sep..

Thomas J.; René K. \& Boel J. (2006). Direct Torque Control of Permanent Magnet Synchronous Motors - An Overview. 3rd IEEE benelux young researchers symposium in electrical power engineering, GHENT, BELGIUM

Kim Y. \& Kook Y. (1999). High Performance IPMSM Drives without Rotational Position Sensors Using Reduced-Order EKF. IEEE Transactions on Energy Conversion, Vol. 14

Shi, K.; Chan, T.; Wong, Y. \& Ho, S. (2000). Speed estimation of an induction motor drive using extended Kalman filter. proceeding IEEE

Pragasan, P. \& Krishnan. R. (1988). Modeling of permanent magnet motor drives. IEEE Trans. Industrial electronics, vol. 35,

Tang, L.; Zhong, L.; Rahman, M. F. \& Hu, Y.( 2002) .A Novel Direct Torque Control for Interior Permanent Magnet Synchronous Machine Drive System with Low Ripple in Torque and Flux-A Speed Sensorless Approach. IEEE Trans Industry Applications Conference, 2002. 37th IAS Annual Meeting. Volume 1, Issue 
Rahman, M. F.; Zhong, L.; Haque, E. \& Rahman, M. A. (2003). A Direct Torque-Controlled Interior Permanent-Magnet Synchronous Motor Drive Without a Speed Sensor. IEEE Trans. Energy conversion, vol. 18, no. 1,

Bhavinkumar, S. (2004). Field oriented control of step motors. Thesis Master of Science. Dept. Elect. Eng Cleveland State Univ. India.

Velázquez, S. C.; Palomares, R. A. \& Segura, A. N. (2004). Speed Estimation for an Induction Motor Using the Extended Kalman Filter. Proceedings of the 14th International Conference on Electronics, Communications and Computers

Yahia, K. ; Menacer, A.; Benakcha, A. ; Benchabane, F. ; \& Taibi , D. (2005). Estimation de la position et de la vitesse du moteur synchrone à aimants permanents en utilisant le filtre de Kalman étendu. First International Conference on Electrical Systems. O. E. Bouaghi Univ. Algeria 


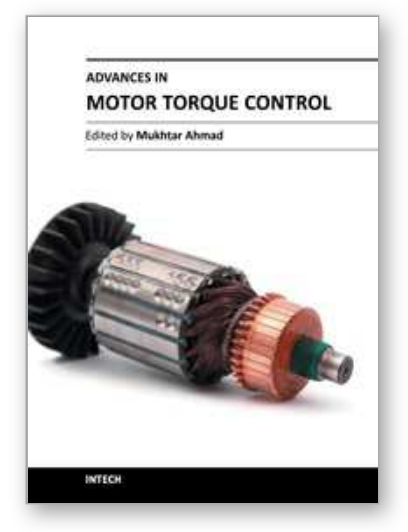

\author{
Advances in Motor Torque Control \\ Edited by Dr. Mukhtar Ahmad
}

ISBN 978-953-307-686-7

Hard cover, 144 pages

Publisher InTech

Published online 22, September, 2011

Published in print edition September, 2011

Electric motors are widely used in industries to convert electrical energy into mechanical form. Control techniques are designed to improve the performance and efficiency of the drive so that large amounts of electrical energy can be saved. This book is primarily written with the objective of providing necessary information on use of electric motors for various applications in industries. During the last ten years a number of methods of control of electric drives have emerged. Some of these methods are described in this book. The reader will be able to understand the new methods of control used in drives, e.g. direct and sensorless control. Also the application of motor control in dentistry, the effect of human reaction and improvement of the efficiency of drives with control have been described.

\title{
How to reference
}

In order to correctly reference this scholarly work, feel free to copy and paste the following:

Merzoug (2011). Speed Estimation Using Extended Filter Kalman for the Direct Torque Controlled Permanent Magnet Synchronous Motor (PMSM), Advances in Motor Torque Control, Dr. Mukhtar Ahmad (Ed.), ISBN: 978-953-307-686-7, InTech, Available from: http://www.intechopen.com/books/advances-in-motor-torquecontrol/speed-estimation-using-extended-filter-kalman-for-the-direct-torque-controlled-permanent-magnetsync

\section{INTECH}

open science | open minds

\author{
InTech Europe \\ University Campus STeP Ri \\ Slavka Krautzeka 83/A \\ 51000 Rijeka, Croatia \\ Phone: +385 (51) 770447 \\ Fax: +385 (51) 686166 \\ www.intechopen.com
}

\author{
InTech China \\ Unit 405, Office Block, Hotel Equatorial Shanghai \\ No.65, Yan An Road (West), Shanghai, 200040, China \\ 中国上海市延安西路65号上海国际贵都大饭店办公楼405单元 \\ Phone: +86-21-62489820 \\ Fax: +86-21-62489821
}


(C) 2011 The Author(s). Licensee IntechOpen. This chapter is distributed under the terms of the Creative Commons Attribution-NonCommercialShareAlike-3.0 License, which permits use, distribution and reproduction for non-commercial purposes, provided the original is properly cited and derivative works building on this content are distributed under the same license. 